\title{
A pilot study using environmental screening to determine the prevalence of Mycobacterium avium subspecies paratuberculosis (MAP) and antimicrobial resistance (AMR) in Irish cattle herds
}

\author{
Elvira Ramovic*, Gillian Madigan, Shannon McDonnell, Denise Griffin, Elaine Bracken, Eadaoin NiGhallchoir,
} Emma Quinless, Aoife Galligan, John Egan and Deirdre M. Prendergast

\begin{abstract}
Background: Dairy and beef cattle can be reservoirs of many pathogens, including Salmonella and Mycobacterium avium subsp. paratuberculosis (MAP), the causative agent of Johne's disease (JD). Farm environments may provide potential entry points for the transmission of infectious agents into the food chain. Antibiotics are used to treat a wide variety of infections on farms, and administration of antimicrobial agents to cattle is considered to be a driving factor for antimicrobial resistance (AMR). Control of JD and AMR are priority for animal health initiatives in Ireland. A national JD pilot programme was introduced by Animal Health Ireland in 2014, while the national action plan launched by Department of Health and Department of Agriculture, Food and Marine introduced in 2017 aims to improve the surveillance of AMR. The current investigation was undertaken as a pilot study to determine the proportion of herds positive for MAP, Salmonella species (Salmonella spp), commensal Escherichia coli (E. coli), Extended-spectrum beta-lactamase (ESBL) AmpC $\beta$ lactamase and carbapenemase-producing E. coli from 157 environmental faecal samples in Irish farms.

Results: MAP was detected in 10.2\% of samples collected; on culture in 4 (4.9\%) of the dairy herds and from 1 (1.3\%) of the beef/suckler herds, and by PCR in 10 (12.3\%) and 6 (7.9\%) of these herds respectively. All culture positive herds were also positive by PCR. An additional 11 herds were positive by PCR only. Salmonella was not detected, while commensal E. coli were isolated from $70.7 \%$ of the samples (111/157) with 101 of these isolates shown to be fully susceptible to all antimicrobials tested. Of the 27 presumptive ESBL AmpC $\beta$-lactamase producing E. coli detected, one isolate was resistant to ten antimicrobials, nine isolates were resistant to nine antimicrobials, and four isolates were resistant to eight antimicrobials. Carbapenemase-producing E. coli were not isolated.

Conclusions: The results highlight the importance of monitoring farm environments for Johne's disease. This disease is a growing concern for dairy and beef producers in Ireland, and sampling the farm environment may offer a useful means to rapidly screen for the presence of MAP. Non-pathogenic common enteric commensal and multiple-drugresistant E. coli may contribute to AMR acting as a reservoir and transferring resistance to other species/pathogens in the environment.
\end{abstract}

Keywords: MAP, Antimicrobial resistance, Salmonella, ESBL, E. coli

\footnotetext{
* Correspondence: Elvira.Ramovic@agriculture.gov.ie

Central Veterinary Research Laboratory, Department of Agriculture, Food and

the Marine, Backweston Complex, Celbridge, Co. Kildare, Ireland
}

(c) The Author(s). 2020 Open Access This article is distributed under the terms of the Creative Commons Attribution 4.0 International License (http://creativecommons.org/licenses/by/4.0/), which permits unrestricted use, distribution, and reproduction in any medium, provided you give appropriate credit to the original author(s) and the source, provide a link to the Creative Commons license, and indicate if changes were made. The Creative Commons Public Domain Dedication waiver (http://creativecommons.org/publicdomain/zero/1.0/) applies to the data made available in this article, unless otherwise stated. 


\section{Background}

A wide variety of bacteria have natural reservoirs on the farm environment which may provide a potential entry point for transmission of infectious agents into the food chain. Therefore the occurrence of various pathogenic microorganisms on farms is of interest. Dairy cattle can be reservoirs of many pathogens, including Salmonella, a major foodborne zoonoses [1, 2] and Mycobacterium avium subsp. paratuberculosis (MAP), the causative agent of Johne's disease (JD) [3]; a chronic intestinal disease in ruminants that may be associated with Crohn's disease in humans [4]. In addition, other bacteria also present in cattle, which may or may not cause disease, and can act as reservoirs of antibiotic resistance which may also transfer to other bacteria or enter the food chain. Escherichia coli forms part of the normal microbiota of humans and animals and can spread through faecal material and wastewater in different environments [5]. Extended-spectrum beta-lactamase (ESBL) producing Enterobacteriaceae have emerged in the last decade as a global threat for human health [6]. They are not only isolated from hospital settings, but they are also disseminated in farm animals, their environments and animal-derived foods [7-11].

The use of antibiotics in veterinary medicine could constitute a selective pressure for the spread of antibiotic resistant bacteria including ESBLs [12]. Antibiotics are used to treat a wide variety of infections affecting animals on farms including respiratory and gastrointestinal diseases, reproductive disorders and mastitis in cows. Administration of antimicrobial agents to cattle is considered to be a driving factor for antimicrobial resistance (AMR) among Salmonella and other enteric pathogens [13-17].

Control of JD and antimicrobial resistance are now priority animal health initiatives in Ireland. A national JD pilot programme has been in operation since 2014 [18] and veterinary practitioners are encouraged to get client farms to participate and undertake herd sampling. Screening herds for antibodies to MAP is the primary method used to detect infection, but its low sensitivity and specificity can be challenging in some herds. Confirmatory testing using culture or PCR is advised to confirm infection in antibody positive animals.

A national action plan aimed at tackling the serious and increasing threat posed by AMR in Ireland was launched jointly by the Department of Health $(\mathrm{DH})$ and Department of Agriculture, Food and the Marine (DAFM) in 2017. Among its five strategic objectives was the need to improve surveillance of AMR. Currently, the AMR surveillance undertaken in Ireland in food and animals is that required under Commission Implementing Decision on the monitoring and reporting of antimicrobial resistance in zoonotic and commensal bacteria [19] and obligatory monitoring focuses on resistance in Salmonella, Campylobacter and E. coli isolated from poultry, pigs and their meat. Currently very little attention is given to AMR on isolates from bovines although diagnostic laboratories in Ireland provide some data on clinical isolates to assist veterinary treatment of infections in these animals.

The current investigation was undertaken as a pilot study to determine the proportion of herds positive for MAP, Salmonella spp., commensal E. coli, ESBL AmpC - $\beta$ lactamase and carbapenemase-producing $E$. coli on Irish farms from environmental faecal samples. The AMR profile in any Salmonella and E. coli isolates as well as the extent of ESBL AmpC $\beta$-lactamase or carbapenemase-producing $E$. coli was also determined.

\section{Methods}

\section{Samples}

Veterinary inspectors in each district office were requested to submit two farm faecal environmental samples, comprised of pooled environmental faeces collected from indoor locations (collecting yards, feeding areas, etc.), from both dairy and beef herds during their inspection visits in Ireland between February and June 2017.

Kits, including disposable gloves and sterile containers, were supplied for sample collection. Once the samples were collected they were submitted immediately by post to the laboratory for testing. Identification of herds was not requested nor was the information on any recent drug treatments, or details on the health status of herds. Once received at the laboratory, sample details (herd type, date and place of sample collection etc.) were recorded and samples were stored at $-20^{\circ} \mathrm{C}$ for a maximum of 6 months before culturing. Prior to testing, the samples were removed from storage at $-20^{\circ} \mathrm{C}$ and defrosted overnight (approx. $18 \mathrm{~h}$ ) at room temperature. The samples were cultured for MAP, Salmonella, commensal E. coli and also examined for the presence of ESBL AmpC $\beta$-lactamase and carbapenemase-producing E. coli.

\section{Statistical analysis}

Test agreement between culture positive and PCR positive samples as well as Kappa value was calculated using https://epitools.ausvet.com.au/ [20]. The strength of agreement was interpreted as follows: value less than 20 was interpreted as poor agreement; values between 0.21-0.40 were fair; $0.41-0.60$ were moderate; $0.61-0.80$ indicated a good agreement, while values above $>0.81$ were described as very good test agreement [21].

\section{MAP culture}

MAP culture was performed using the Cornell double incubation decontamination method as previously described by Kim et al. (2002) [22]. In brief, after suspending faeces in $35 \mathrm{ml}$ sterile water, the $5 \mathrm{ml}$ from the top portion of the sample was transferred to $25 \mathrm{ml}$ of $0.9 \%$ hexadexcylpiridinium chloride (HPC) (Sigma Aldrich) 
and incubated for $18-24 \mathrm{~h}$ at $37^{\circ} \mathrm{C}$, followed by an additional 18-24h incubation in antibiotic brew (Trek diagnostic systems, Thermo Scientific, US). Samples were then inoculated into Trek bottles with added growth supplements for incubation at $37^{\circ} \mathrm{C}$ for 42 days of continuous monitoring by the Versa Trek system (Trek diagnostic systems, Thermo Scientific, US). Positive and negative Versa Trek signal samples were subjected to Ziehl-Neelsen (ZN) staining, and samples that contained acid fast bacilli (AFB) and were further confirmed for MAP using mycobactin dependence [23] and F57 PCR [24] assays. MAP levels in samples were determined as described by Lombard et al. (2006) [25] using the days to positivity on the Versa Trek system. Samples signaling positive in the first 21 days of incubation indicated high MAP levels present, between 22 and 28 days indicated moderate MAP levels present, signals between 29 and 35 and 36-42 days indicated the presence of low and very low levels, respectively.

\section{Direct MAP PCR}

Direct faecal PCR was carried out using the spin column (Qiagen DNA mini kit, Qiagen Ltd., Manchester, UK) extraction method [26] and LSI VetMAX M. paratuberculosis Advanced Real Time PCR kit (Thermo Fisher Scientific) targeting the IS900 sequence, following manufacturer's extraction and purification recommendations. In brief, $2 \mathrm{~g}$ of faecal sample was suspended in $30 \mathrm{~mL}$ of sterile DNA/RNA free water and $3.6 \mathrm{~mL}$ from the top layer was used to obtain pellet. The buffer was added to the pellet and the sample was disrupted using the tissue lyser (Qiagen). Tissue lysis buffer and internal positive control (IPC) was further added to the sample and DNA extraction was carried out using the buffers and silica gel membrane spin column as described in part by Sting et al. (2014) [27]. In brief, ethanol and buffers (Qiagen) were added to the sample, and MAP DNA was eluted from spin column using elution buffer (Qiagen). Master mix containing buffer, real time PCR enzymes, sequence pool (LSI VetMAX) and $5 \mu$ l of eluted DNA was prepared and samples were analyzed using the Stratagene MxPro3005 thermo cycler, and a $\mathrm{Ct}$ value of less than 45 cycles was considered positive for MAP as recommended by the kit manufacturer.

Individual controls were included for each test to ensure validity of the test results and compliance with the accredited standards used in the testing laboratory.

\section{Isolation of commensal $E$. coli}

Using a sterile cotton swab, the faecal sample was mixed thoroughly against the side of the sample container. The swab was streaked directly onto MacConkey (MAC) agar No. 3, E\&O Laboratories Ltd., UK [Cat \#: PP1720]) and then triple streaked using a sterile loop to isolate single colonies $[28,29]$. The plates were incubated at $37^{\circ} \mathrm{C} \pm$
$1{ }^{\circ} \mathrm{C}$ for $20 \pm 2 \mathrm{~h}$ and examined for typical $E$. coli growth (purple/red colonies). Typical colonies were subcultured onto Brilliance ${ }^{\mathrm{TM}}$ E. coli/Coliform (BECC) medium (Fannin L.I.P, Ireland [Cat\#: W11106]), incubated at $37 \pm 1{ }^{\circ} \mathrm{C}$ for $20 \pm 2 \mathrm{~h}$ and examined for typical E. coli growth (purple colonies).

\section{Pre-enrichment of samples}

A pre-enrichment step was performed by weighing $25 \pm 1 \mathrm{~g}$ into a stomacher bag using a Dilumat (AES International). The sample was diluted 1 in 10 with Buffered Peptone Water (BPW) ISO (LAB M Ltd., Lancashire, UK), homogenised by stomaching for $1 \mathrm{~min}$ ( $360 \mathrm{cycles} / \mathrm{min}$; speed setting 6) (Interscience BagMixer ${ }^{\circ} 400 \mathrm{P}$ ) and incubated at $37 \pm 1^{\circ} \mathrm{C}$ for $18 \pm 2 \mathrm{~h}$. The pre-enriched samples were examined for the presence of ESBL AmpC $\beta$-lactamase and carbapenemase-producing E. coli and Salmonella following the laboratory protocol described by the EU Reference Laboratory for antimicrobial resistance [30].

\section{Isolation of $\mathrm{ESBL} / \mathrm{AmpC}$ producing $E$. coli}

Following overnight pre-enrichment, samples were gently mixed by hand and a $10 \mu \mathrm{l}$ loopful of the enriched BPW was inoculated onto a MAC plate containing $1 \mathrm{mg} \mathrm{L}^{-1}$ cefotaxime (CTX) (E\&O Laboratories, Cat \#: PP0478). The plates were incubated at $44 \pm 0.5^{\circ} \mathrm{C}$ for $20 \pm 2 \mathrm{~h}$ and examined for typical $E$. coli growth as described above. Presumptive ESBL AmpC $\beta$-lactamase producing E. coli colonies were sub-cultured onto MAC agar plates containing $1 \mathrm{mg}$ $\mathrm{L}^{-1} \mathrm{CTX}$ and incubated at $37 \pm 1{ }^{\circ} \mathrm{C}$ for $20 \pm 2 \mathrm{~h}$. For species identification, suspect colonies were sub-cultured onto BECC plates, incubated at $37 \pm 1^{\circ} \mathrm{C}$ for $20 \pm 2 \mathrm{~h}$ and examined for typical growth.

\section{Isolation of carbapenemase-producing $E$. coli}

For isolation of carbapenemase-producing E. coli including strains producing only OXA-48 like enzymes, preenriched samples were gently mixed as above and a $10 \mu \mathrm{l}$ loopful of the BPW was streaked onto onto a chromID ${ }^{\mathrm{Tm}}$ CARBA plate (Biomérieux, Cat \#: 43861) and chromID ${ }^{\text {TM }}$ OXA-48 plate (Biomérieux, Cat \#: 4414011) and incubated at $44 \pm 1{ }^{\circ} \mathrm{C}$ for $20 \pm 2 \mathrm{~h}$. The plates were examined for typical $E$. coli growth (mauve colonies on both plate types). Presumptive colonies were subcultured onto MAC plates followed by BECC plates and examined for typical growth as described above for isolation of ESBL AmpC $\beta$ lactamase producing E. coli.

\section{Salmonella isolation}

Salmonella were isolated following the standard protocol [31]. In brief, $100 \pm 5 \mu \mathrm{l}$ of the pre-enriched BPW was inoculated onto Modified semi-solid Rappaport Vassiliadis (MSRV) medium by placing 3 equidistant drops onto the surface of the agar in the central area of the plate. 
The inoculated MSRV plates were incubated at $41.5 \pm$ $1{ }^{\circ} \mathrm{C}$ for $24 / 48 \pm 3 \mathrm{~h}$. Following $24 \mathrm{~h}$ incubation, or $48 \mathrm{~h}$ if no growth was observed at $24 \mathrm{~h}$, presumptive Salmonella positive growth (turbid zone characterised by a white halo with a clearly defined edge) was subcultured onto Xylose Lysine Deoxycholate (XLD) (E\&O Laboratories) and Modified Brilliant Green (MBG) selective agar plates (E\&O Laboratories, Cat \#: PP0320 and PP0060, respectively). The selective agar was incubated at $37 \pm 1{ }^{\circ} \mathrm{C}$ for $24 \pm 3 \mathrm{~h}$ and checked for typical Salmonella growth (black colonies on XLD agar and pink/red colonies on MBG agar). Any suspect colonies were sub-cultured onto Colorex Salmonella Plus (CHROMagar) (E\&O Laboratories, Cat \#: PP1071) plates, incubated at $37 \pm 1{ }^{\circ} \mathrm{C}$ for $24 \pm 3 \mathrm{~h}$ and examined for typical mauve coloured colonies for Salmonella growth.

\section{Species identification of $E$. coli and Salmonella}

Presumptive E. coli, ESBL AmpC $\beta$-lactamase, carbapenemase-producing E. coli and Salmonella colonies were inoculated onto Nutrient Agar (NA; E\&O Laboratories, Cat \#: PP0690) and incubated at $37 \pm 1{ }^{\circ} \mathrm{C}$ for $20 \pm 2 \mathrm{~h}$.

The MALDI Biotyper was used to identify microorganisms using MALDI-ToF (Matrix Assisted Laser Desorption Ionization-Time of Flight) Mass Spectrometry (Bruker Daltronics GmbH, Bremen, Germany). An individual colony from a NA plate was spotted onto the ground steel target plate (MSP 96 target polished steel reusable slides with barcode) of the MALDI-ToF. The entire spot was then overlain with $1 \mu \mathrm{l}$ of pre prepared $\alpha$-Cyano4-hydroxycinnamic acid (HCCA) matrix solution and allowed to air dry. The matrix solution was prepared by adding $250 \mu \mathrm{l}$ standard solvent (50\% acetonitrile, $47.5 \%$ HPLC Water, 2.5\% Trifluoroacetic acid) to the contents of one tube of Bruker HCCA Matrix to give a final HCCA concentration of $10 \mathrm{mg} \mathrm{mL}^{-1}$. The solution was vortexed for approximately $10 \mathrm{~s}$ at room temperature followed by a $10 \mathrm{~s}$ spin in a mini centrifuge. This solution was stored at room temperature for up to 1 week.

Once the matrix was dry, the target plate was loaded onto the MALDI-ToF and measurements were performed with microflex mass spectrometer of the MALDI-ToF instrument using Compass software. The results were collected electronically in spectral channels and converted from TOF measurements into mass/charge values. A value ranging from 2.00 to 3.00 was interpreted as a highly probable species level identification [32].

In addition to the test samples, a bacterial test standard (BTS) quality control sample was included with each run for instrument calibration to ensure reliable and accurate identification of microorganisms. Pre-prepared BTS was added to the slides and overlaid with matrix as described above for each of the samples. The BTS was prepared by removing one tube of BTS (Bruker) from storage at $-18^{\circ} \mathrm{C}$, equilibrated to room temperature and $50 \mu \mathrm{l}$ of standard solvent was added. BTS was dissolved by pipetting up and down at least 20 times. The standard was centrifuged at 13,000 RPM for $2 \mathrm{~min}$ at room temperature. Aliquots $(5 \mu \mathrm{l})$ of the supernatant were pipetted into $0.5 \mathrm{~mL}$ screw-cap micro tubes and stored at $-18{ }^{\circ} \mathrm{C}$. Frozen, dissolved BTS were stored for up to 5 months at $-18^{\circ} \mathrm{C}$.

All isolates confirmed by MALDI-ToF were stored at $-80^{\circ} \mathrm{C}$ in Protect beads (Technical Service Consultants Ltd., Lancashire, U.K) prior to testing for AMR.

\section{AMR susceptibility testing of commensal $E$. coli}

AMR testing was carried out using broth microdilution according to the regulation [19] and the results recorded as the Minimum Inhibitor Concentration (MIC) which is the lowest concentration of antimicrobial without visible growth. Beads were grown on Columbia Agar Base with 5\% Defibrinated Horse Blood (E\&O Laboratories, Cat \#: PP0120) at $37 \pm 1{ }^{\circ} \mathrm{C}$ for $20 \pm 2 \mathrm{~h}$ and examined for pure growth. A 0.5 McFarland culture solution $\left(1.5 \times 10^{8} \mathrm{CFU} /\right.$ $\mathrm{mL}$ ) [33] was prepared by suspending several colonies in demineralised water (Sensititre, Cat \#: T3339) and adjusting the turbidity using a nephelometer (Sensititre). The 0.5 McFarland culture suspension was diluted by adding $10 \mu \mathrm{l}$ of the suspension to a tube of Cation-adjusted Mueller-Hinton broth $(\mathrm{MH})$ broth (Sensititre, Cat \#: T3462) and mixed by inversion. Using an autoinoculator (ThermoFisher), the solution was inoculated onto EUVSEC Sensititre broth microdilution antimicrobial susceptibility plates (TREK Diagnostic Systems), $50 \mu \mathrm{l}$ per well. The plates were sealed and incubated at $37 \pm 1^{\circ} \mathrm{C}$ for $20 \pm 2 \mathrm{~h}$. The following antibiotics were tested: Amp (ampicillin), Azi (azitromycin), Ctx (cefotaxime), Caz (ceftazidime), Chl (chloramphenicol), Cip (ciprofloxacin), Col (colistin), Gen (gentamicin), Mer (meropenem), Nal (nalidixic acid), Smx (sulphamethoxazole), Tet (tetracycline) and Tmp (trimethoprim). A post-sensitivity purity check was carried out by subculturing $1 \mu \mathrm{l}$ of culture from the positive control well on the AMR plate onto a BA plate and incubated at $37.0 \pm 1{ }^{\circ} \mathrm{C}$ for $20 \pm 2 \mathrm{~h}$. The AMR plate was read visually using an automatic Vizion plate reader (ThermoFisher) to determine the MIC. A control strain of E. coli 25,922 was tested alongside each batch of samples. The interpretation of the results, susceptible or resistant to a given antimicrobial, was carried out based on the EU decision [19].

\section{AMR susceptibility testing of $E$. coli, ESBL AmpC $\beta$ - lactamase and carbapenemase-producing $E$. coli}

AMR testing on presumptive E. coli, ESBL AmpC $\beta$ lactamase and carbapenemase-producing $E$. coli was performed using the two-step approach, i.e. both testing panels (EUVSEC and EUVSEC2). From the first panel 
(EUVSEC), E. coli strains which exhibited resistance to cefotaxime, ceftazidime and/or meropenem were further tested using the ESBL microtitre plate EUVSEC2.

The procedure that was followed was identical to the method outlined above for EUVSEC plates. The following antibiotics were tested: Fep (cefepime), Ctx (cefotaxime), CTX-C (cefotaxime/clavulanic acid), Fox (cefoxitin), Caz (ceftazidime), CAZ-C (ceftazidime/clavulanic acid), Etp (ertapenem), Imi (imipenem), Mer (meropenem) and Tem (temocillin). This second plate was used as a confirmatory test for ESBL production and required the use of both cefotaxime and ceftazidime alone or in combination with a $\beta$-lactamase inhibitor (Clavulanic acid). Synergy was defined as a $\geq 3$ dilution decrease in MIC tested (in combination with clavulanic acid vs alone). The classification of the phenotypic results was based on the most recent EFSA recommendations [34].

\section{Results}

Environmental faecal samples were collected from a total of 157 farms; 81 of which were dairy herds and 76 beef/ suckler herds. The farms were distributed in 24 counties throughout Ireland; $43.1 \%$ in Munster, $19.6 \%$ in Leinster, and 15.7 and $21.6 \%$ in Connacht and Ulster respectively. No information of geographical location was obtained for 4 farms.

MAP was detected on culture in $4(4.9 \%)$ of the dairy herds and from $1(1.3 \%)$ of the beef/suckler herds and by PCR in $10(12.3 \%)$ and $6(7.9 \%)$ of these herds respectively. Kappa value between culture and PCR was calculated at 0.45 (95\% CI 0.19 to 0.71$)$ with overall proportion agreement calculated at 0.93. All the culture positive herds were also positive on PCR (Table 1).

Of the 5 culture positive samples, one was recorded as containing a high level of MAP, one a moderate level, and three samples as having very low levels of MAP present. Mean Ct value for culture positive samples was recorded at 31.75 (range: 29.43-33.46), while the mean $\mathrm{Ct}$ value for culture negative but PCR positive samples was 35.18 (range: $33.14-37.08$ ).

Table 1 Environmental screening results of dairy and beef herds using culture and direct PCR assays

\begin{tabular}{llll}
\hline Province & $\begin{array}{l}\text { Herd Type } \\
\text { Dairy / Beef }\end{array}$ & \multicolumn{2}{l}{ Number of positive herds by Culture / PCR } \\
\cline { 3 - 4 } & & Dairy & Beef $^{\mathrm{a}}$ \\
\hline Munster & $37 / 29$ & $2 / 6$ & $0 / 3$ \\
Leinster & $18 / 12$ & $0 / 0$ & $0 / 1$ \\
Connacht & $9 / 15$ & $0 / 1$ & $0 / 1$ \\
Ulster & $14 / 19$ & $2 / 3$ & $0 / 0$ \\
Total $^{c}$ & $78 / 75$ & $4 / 10$ & $0 / 5$ \\
\hline
\end{tabular}

${ }^{\text {a }}$ Three herds were recorded negative on both culture and PCR

${ }^{b}$ One herd was recorded positive on both culture and PCR

${ }^{\mathrm{C}}$ Additional four herds were screened with unknown geographical location
Salmonella spp. was not isolated from any of the environmental samples. Commensal E. coli were isolated from 111 of the 157 samples. Following AMR, 101 of these isolates were shown to be fully susceptible to all antimicrobials tested (Table 2). Five were resistant to four antimicrobials with resistant patterns of Amp, Chl, Smx, Tet in four isolates and Amp, Chl, Cip, Nal in one isolate. Four isolates were resistant to three antimicrobials displaying resistant profiles of Amp, Smx, Tet and one isolate was resistant to two antimicrobials showing a resistant profile of $\operatorname{Smx}$, Tet (Table 2).

Following screening for the presence of ESBL, AmpC and carbapenemase-producing E. coli, 27 presumptive ESBL AmpC $\beta$-lactamase producing E. coli were isolated. No Carbapenemase E. coli were isolated. AMR on EUVSEC plates displayed 14 different AMR profiles for the 27 isolates (Table 3). One isolate was resistant to ten different antimicrobials (Amp, Ctx, Caz, Chl, Cip, Gen, Nal, Smx, Tet, Tmp), nine isolates were resistant to nine antimicrobials displaying four different AMR profiles and four isolates were resistant to eight antimicrobials displaying three different AMR profiles (Table 3).

All 27 presumptive ESBL AmpC $\beta$-lactamase isolates on EUVSEC plates were resistant to either Cefotaxime, Ceftazidime or both, and therefore EUVSEC2 plates were applied to these isolates. The results on EUVSEC2 plates permitted the final interpretation of ESBL Phenotype/Presumptive ESBL producer (nine isolates), Presumptive ESBL + pAMPC producer (3 isolates) and presumptive pAmpC phenotype/Presumptive AmpC producer (15 isolates) as shown in Table 3.

\section{Discussion}

The farm is a dynamic environment and represents a possible entry point for pathogens directly into the food chain and indirectly through their dissemination into the agroecosystem through land-spreading of manures as nutrient sources for growing crops [35]. Once spread with manure to agricultural land, pathogens can survive for extended periods [3, 36-39] leading to the opportunity for

Table 2 AMR profile of 111 commensal E. coli isolated from farm environmental samples

\begin{tabular}{|c|c|}
\hline AMR Profile & Number of Isolates \\
\hline Fully susceptible & 101 \\
\hline $\mathrm{Amp}^{\mathrm{a}}, \mathrm{Chl}^{\mathrm{b}}, \mathrm{Sm}^{\mathrm{c}}$, Tet $^{\mathrm{d}}$ & 4 \\
\hline Amp, Smx, Tet & 4 \\
\hline Amp, Chl, Cip ${ }^{e}, \mathrm{Nal}^{f}$ & 1 \\
\hline Smx, Tet & 1 \\
\hline $\begin{array}{l}{ }^{\mathrm{a}} \text { Ampicillin } \\
{ }^{\mathrm{b}} \text { Chloramphenicol } \\
{ }^{\mathrm{c}} \text { Sulphamethoxazole } \\
{ }^{\mathrm{d}} \text { Tetracycline } \\
{ }^{\mathrm{e}} \text { Ciprofloxacin } \\
{ }^{\mathrm{f}} \text { Nalidixic acid }\end{array}$ & \\
\hline
\end{tabular}


Table 3 AMR profile of 27 presumptive ESBL AmpC $\beta$-lactamase E. coli isolated from farm environmental samples

\begin{tabular}{|c|c|c|c|}
\hline AMR profile EUVSEC & EUVSEC 2 & Final Interpretation ${ }^{a}$ & Number of Isolates \\
\hline Amp Ctx Caz Cip Nal Smx Tet Tmp & Fep Ctx Caz & Presumptive ESBL & 1 \\
\hline Amp Ctx Caz & Fep Ctx Fox Caz & Presumptive ESBL & 1 \\
\hline Amp Ctx Caz Chl Cip Nal Smx Tet Tmp & Fep Ctx Caz & Presumptive ESBL & 3 \\
\hline Amp Ctx Caz Cip Nal Smx Tet Tmp & Fep Ctx Caz & Presumptive ESBL & 1 \\
\hline Amp Ctx Caz Chl Cip Nal Smx Tmp & Fep Ctx Caz & Presumptive ESBL & 2 \\
\hline Amp Ctx Caz & Ctx Caz & Presumptive ESBL & 1 \\
\hline Amp Ctx Caz & Fep Ctx Fox Caz Etp & Presumptive ESBL + pAmpC & 1 \\
\hline Amp Ctx Caz & Fep Ctx Fox Caz & Presumptive ESBL + pAmpC & 1 \\
\hline Amp Ctx Caz Chl Cip Nal Smx Tet Tmp & Fep Ctx Fox Caz & Presumptive ESBL + pAmpC & 1 \\
\hline Amp Ctx Caz & Ctx Fox Caz & Presumptive $\mathrm{pAmpC}$ & 1 \\
\hline Amp Ctx Caz Chl Cip Gen Nal Smx Tet Tmp & Ctx Fox Caz & Presumptive $\mathrm{pAmpC}$ & 1 \\
\hline Amp Ctx Caz Chl Cip Gen Nal Smx Tmp & Ctx Fox Caz & Presumptive $\mathrm{pAmpC}$ & 2 \\
\hline Amp Ctx Caz Chl Cip Nal Smx Tet Tmp & Ctx Fox Caz & Presumptive $\mathrm{pAmpC}$ & 3 \\
\hline Amp Ctx Caz Smx Tet & Ctx Fox Caz & Presumptive $\mathrm{pAmpC}$ & 8 \\
\hline
\end{tabular}

${ }^{a}$ Interpretation based on EFSA recommendations

contamination of food production and water supply systems [40, 41]. Cattle can be reservoirs for several pathogens, including Salmonella [1,2] and MAP, the causative organism for Johne's disease [3] a chronic intestinal disease in ruminants that may be associated with Crohn's disease in humans [4]. Sampling the farm environment can therefore be a useful and convenient way [42-44] of screening for the presence of various pathogens, not unlike the analysis of boot swabs collected from the poultry farm environment which are routinely used for monitoring the presence of notifiable Salmonella [45].

Johne's disease is a growing concern for dairy and beef producers in Ireland and elsewhere and programmes for its control are in place in many countries. MAP, the etiologic agent of Johne's disease is a growing concern in Irish cattle herds and has been considered by some to be a potential emerging foodborne pathogen [35, 46-52]. Estimates of its prevalence in many countries vary and diagnostic tests have limited sensitivity, particularly for detecting early stages of infection [53]. Serological surveys estimate herd prevalence in dairy herds at $80-86 \%$ in Denmark, $65 \%$ in the UK and between 20 and $71 \%$ in Netherlands [54]. In Ireland [55], calculated seroprevalence at $21.4 \%$ with dairy herds having a higher incidence (31.5\%) than beef herds (17.9\%) while in a more recent study McAloon et al (2016) [56] using Bayesian analysis, calculated the true herd prevalence in the region of 23$34 \%$. The current study is the first here in Ireland to use environmental sampling to estimate the extent of MAP on farms. Results of this study showed that MAP was detected in 16/157 farms and confirmed on culture in 4 (4.9\%) dairy herds and 1 (1.3\%) of the beef/suckler herds. Other Irish researchers have screened milk sock filter residue (MRF) [57] to estimate MAP prevalence on dairy farms and found 44\% [26] compared to 20\% MFR culture positive herds. In that study, among the 12 MFR culture positive herds, each was positive at only one of the six testing events over the two-year period.

A number of diagnostic tests are available for the detection of MAP, each with positive and negative attributes. Serological testing of animals is the primary screening method applied in Ireland for the detection of infected herds with follow up confirmatory testing of faeces from suspect animals by culture or PCR. Concerns about the ELISA test are reported as climate and cattle management systems on some Irish farms predispose animals through exposure to environmental mycobacteria and it is recognised that such exposure may give rise to non-specific or false positive MAP ELISA reactions [41, 58]. The Irish climate and abundant rainfall allow up to 10 months of pasture production per year; pasture based rotational systems are the norm on Irish dairy farms $[59,60]$. Cross reaction to MAP may also result from administration of tuberculin $[61,62]$ which is used in the bovine tuberculosis control programme in Ireland [63] contributing to non-specific or false positive MAP ELISA reactions. In view of these concerns it might be opportune to further examine environmental sampling for MAP as an alternative screening method.

Cultivation of MAP, although expensive and slow still remains the "gold standard" diagnostic test for the disease [64] with an ante-mortem specificity of $100 \%$ $[43,65]$ and a sensitivity varying from 30 to $50 \%$ [25, 66-68]. Sensitivity of culture on a herd level is affected by the number of shedders present and their shedding levels $[69,70]$. Seasonal influences may also affect culture in so far as increased fungal growth in faeces during the warmer season may not be fully removed during the 
decontamination process used in the culture method resulting in culture negative samples $[3,69,71]$. PCR is emerging as a comparable method to culture and can be completed in a day compared to up to 42 days or longer required for the culture results [26, 72]. Sensitivity of PCR is reported to be between 70 and $100 \%$, depending on infection stage and pre-treatment methods applied in DNA extraction $[65,73]$, with specificity considered to be $100 \%[27,73]$. The inclusion of physical or chemical steps to improve DNA extraction, as well as the use of alternative MAP targets [74] have been shown to improve the sensitivity of the kits $[75,76]$. While the $I S 900$ sequence is considered highly sensitive and specific for MAP, a positive signal has also been reported from environmental mycobacteria [22, 77]. , Eisenberg et al. (2010, 2012) [78-80] suggested that the positive direct faecal PCR results may indicate presence of infection while other researchers $[22,77,81]$ found that in absence of a more specific test (culture or F57 PCR), positive PCR results may indicate presence of mycobacterial DNA only. Ct values are inversely related to the amount of MAP in the sample 72,82] and may be indicative of the presence of high shedders on farms. Although we applied the Ct cut off threshold of $<45$ cycles for the test (as recommended by the manufacturer), Prendergast et al. (2018) [26] also found a somewhat similar threshold of 43.67 for this kit when applied to a well-defined sample population. As PCR testing is also limited by its inability to distinguish between viable and non-viable MAP cells $[82,83]$, caution in the interpretation of the PCR results is advised.

In our study, the culture positive samples were also positive on PCR (moderate Kappa value). Both culture and PCR results suggested the presence of high or moderate shedders in two farms. As no information was available on the MAP infection status of the herds it was not possible to draw any definitive conclusions on the respective merits of both tests for screening herds using environmental samples. As inclusion of more environmental samples does not improve the faecal culture positive recovery, repeated sampling of environment is recommended [69]. Although MAP herd prevalence in dairy herds is higher than in the beef herds in Ireland [55], environmental testing in beef herds is considered to be a reliable screening method for MAP [84].

In addition, storage of some samples for up to 6 months prior to culture may have resulted in a reduction of viable MAP in faeces [85], and may have accounted for some of the differences between the culture and PCR results presented in this study. Bovine salmonellosis is also a common disease on some Irish farms routinely identified as a cause of abortion or neo natal mortality and other infections [86, 87]. In 2015 S. Dublin, for instance, accounted for a total of $4.8 \%$ of the total foetal abortions [88]. S. Typhimurium is associated with acute enteritis $[89,90]$ and can survive in multiple different environments for extensive periods of time. According to Andino \& Hanning (2015) [91] the prevalence of Salmonella in farm environments has been documented to range from 10 to $25 \%$. Strohmeyer et al. (2006), Weese et al. (2005) and Joffe \& Schlesinger (2002) [92-94] reported presence of Salmonella in 5.9, 20 and $80 \%$ of samples respectively in commercially available raw meats used for canine and feline diets. Rodrigues et al. (2006) [95] also reported the Salmonella presence in $10.4 \%$ of soil samples on bovine dairy farms. Although Salmonella spp. were not isolated from environmental samples in this study it may be due to the small number of farms tested and with testing only undertaken once during the spring months this may have limited the chances of its detection.

Antibiotic treatments given in animal husbandry are similar to human medicine [96]. As the amount of antimicrobial agents used for therapeutic and nontherapeutic purposes in agriculture is used for humans in many parts of the world [97], it is increasingly being considered a global health issue; both from the animal health and welfare aspect and because of the development of antibiotic resistance in animal pathogens [98, 99]. In addition, animal manure is a major source of antimicrobial resistant bacteria entering the environment, especially the soil used as fertilizer on agricultural land in the UK [100]. Much of this will contain low levels of antibiotics or antibiotic metabolites/conjugates, and antimicrobial resistant bacteria.

Non-pathogenic, multiple-drug-resistant $E$. coli in the intestine is an important reservoir of resistance genes [101-103]. The bacterium is one of the group of seven species that the world health organisation (WHO) has highlighted as of key AMR concern and serves as a sentinel organism for antimicrobial resistance in different types of animals. Because it is a common enteric commensal, it can be a pathogen, and easily acquires resistance and therefore can act as a reservoir that can transfer resistance to other species/pathogens [104-108]. Intestinal E. coli of animal origin may also colonize the human intestine, at least temporarily [109]. Bolton et al. (2014) [110] noted that over $60 \%$ of $E$. coli directly isolated were fully susceptible to the antibiotics tested with resistance where found being mainly to older antibiotics such as oxytetracycline and sulphonamide. Other studies [111] have reported most strains of $\boldsymbol{E}$. coli isolated from cattle, were resistant to ampicillin (64\%), tetracycline (74\%), streptomycin (60\%) and sulphonamide $(76 \%)$ with low occurrence $(1 \%)$ of enrofloxacin resistance, and in a later study by [112], all the $\boldsymbol{E}$. coli isolates from dairy calves and lambs showed multi-resistance to tetracycline, streptomycin and compound sulphonamides with less resistance to enrofloxacin.

The emergence and spread of extended spectrum $\beta$ lactamase (ESBL)-producing E. coli associated with cattle 
and other farm animals [113-115] is a growing concern as both ESBL and AmpC $\beta$-lactamases can confer resistance to third-generation cephalosporins, penicillins and monobactams. These distinct enzymes can be differentiated by different susceptibility patterns against $\beta$-lactam site-specific inhibitors such as clavulanic acid and their differences in activity against fourth-generation cephalosporins [113, 116-118]. In this present study, 17.2\% (27/ 157) of samples cultured on MAC agar plates containing $1 \mathrm{mg} \mathrm{L}^{-1}$ CTX were identified as presumptive ESBL AmpC $\beta$-lactamase producing E. coli. These 27 presumptive ESBL AmpC $\beta$-lactamase producing E. coli underwent susceptibility testing which permitted isolates to be assigned ESBL or AmpC categories on the basis of their resistance patterns i.e., nine isolates ( $5.7 \%$ of samples) were identified to be ESBL producing $E$. coli, three isolates $(0.2 \%)$ were identified to be ESBL and AmpC producing $E$. coli and 15 (9.6\%) were identified to be AmpC producing E. coli. This trend i.e., highest number of presumptive ESBL AmpC $\beta$-lactamase positive samples identified as AmpC positive and lowest numbers positive for both ESBL AmpC $\beta$-lactamase has been previously reported to be observed in pig intestinal contents collected at slaughter during 2015 in Ireland and this trend has also been reported to be observed in the EU [119]. Carbapenemase-producing $E$. coli were not observed in the present study and this has also been reported previously by O'Sullivan et al. (2016) [119] for pig caeca, pork and beef during 2015 and chicken caeca and meat during 2016 in Ireland. Significant amounts of antibiotics are used within the agriculture sector in Ireland and it is estimated that $88 \%$ of veterinary antimicrobials administered consist of formulations of older antibiotics, such as penicillin, tetracycline and aminoglycosides [120].

The World Health Organisation (WHO) has initiated a number of global efforts to tackle the AMR problem including the categorisation of antimicrobials used in human health as critically important [121]. In 2014, the EU introduced harmonized monitoring of AMR across selected bacteria isolated from food and animals in Member States [19]. A panel of 14 antimicrobials were selected for monitoring using the micro broth dilution method EUVSEC Sensititre and EUCAST thresholds for resistance with testing undertaken in National Reference Laboratories, including our laboratory. While the results of this study demonstrated the prevalence of resistance to two critically important antibiotics, it was reassuring to note that the fluoroquinolone resistance was caused by a chromosomal mutation and not plasmid mediated i.e. resistant to both ciprofloxacin and nalidixic acid [122]. It would have been of value to carry out further analysis of these organisms using whole genome sequencing (WGS) to characterise the ESBL-encoding genes and identify additional antimicrobial resistance genes. In addition WGS would have been of value to determine genetic relatedness of the organisms by multi locus sequence typing (MLST).

The total tonnage of veterinary antibiotics used in Ireland was $103.4 \mathrm{t}$ in 2016 , and the most commonly sold antimicrobials for animal used in Ireland were tetracyclines (39.9\%), sulphonamides \& trimethoprim (20.7\%) and penicillins (20.4\%) [123]. This shows that tetracyclines and penicillins continue to comprise a significant portion of veterinary antibiotics used in Ireland. Also included in this report [123] were sales of 3rd and 4th generation cephalosporins and showed that these sales have generally remained unchanged over the last 4 years.

\section{Conclusions}

The results of this study highlight the potential value of monitoring the farm environment for Johne's disease; a growing concern for dairy and beef producers in Ireland and sampling the farm environment may provide a convenient way to rapidly screen herds for the presence of MAP. While it was reassuring that no carbapenemaseproducing $E$. coli was observed in this study the presence of ESBL AmpC $\beta$-lactamase in environmental samples highlights the importance of monitoring samples for both cephalosporins and carbapenem classes since the $E$. coli producing ESBLs allows them to become resistant to most of the beta lactam antimicrobials. Further investigation of the value of farm environmental monitoring for Johne's disease and AMR is recommended.

\section{Acknowledgements}

The authors wish to acknowledge the help of veterinary inspectors for their input in sample collection.

\section{Authors' contributions \\ The study's conception and design was done by J.E who also contributed to writing and editing of the manuscript. Sample collection was supervised by S.MCD. D.P and E.R co-ordinated testing, data interpretation and contributed to writing the manuscript. G.M tested and supervised testing of samples and in part contributed to writing of AMR materials and methods. E.N in part tested, and supervised sample testing. S.McD, D.G., E.B., A.G and E.Q also carried out the testing of samples. All authors read and approved the final manuscript.}

\section{Funding}

N/A.

\section{Availability of data and materials \\ The datasets used and/or analysed during the current study are available from the corresponding author on reasonable request.}

\section{Ethics approval and consent to participate} N/A.

\section{Consent for publication}

N/A.

Competing interests

The authors declare that they have no competing interests. 
Received: 18 July 2019 Accepted: 26 January 2020

\section{Published online: 15 February 2020}

\section{References}

1. Blau DM, Cluskey BJMC, Ladely SR, Dargatz DA, Fedorka-Cray PJ, Ferris KE. Salmonella in dairy operations in the United States: prevalence and antimicrobial drug susceptibility. J Food Prot. 2005;68(w):696-702.

2. Huston CL, Wittum TE, Love BC, Keen JE. Prevalence of fecal shedding of Salmonella spp in dairy herds. J Am Vet Med Assoc. 2002;220:645-9.

3. Whittington RJ, Marshall DJ, Nicholls PJ, Marsh IB, Reddacliff LA. Survival and dormancy of Mycobacterium avium subsp. paratuberculosis in the environment. Appl Environ Microbiol. 2004;70:2989-3004.

4. Over K, Crandall PG, Bryan CAO, Ricke SC. Current perspectives on Mycobacterium avium subsp. paratuberculosis, Johne's disease, and Crohn's disease: a review. Crit Rev Microbiol. 2011;37:141-56.

5. Bain R, Cronk R, Hossain R, Bonjour S, Onda K, Wright J, et al. Global assessment of exposure to faecal contamination through drinking water based on a systematic review. Tropical Med Int Health. 2014;19:917-27.

6. Pitout JDD, Laupland KB. Extended spectrum $\beta$-lactamase producing Enterobacteriaceae: an emerging public-health concern. Lancet Infect Dis. 2008;8:159-66

7. Jouini A, Vinue L, Ben SK, Sanez Y, Klibi N, Hammami S, et al. Characterization of CTX-M and SHV extended-spectrum b-actamases and associated resistance genes in Escherichia coli strains of food samples in Tunisia. J Antimicrob Chemother. 2007;60:1137-41.

8. Poeta P, Radhouani H, Pinto L, Martinho A, Rego V, Rodrigues R, et al. Wild boars as reservoirs of extended-spectrum beta-lactamase (ESBL) porducing Escherichia coli of different phylogenetic groups. J Basic Mirobiol. 2009;49: 584-8.

9. Vinue L, Saenz Y, Martinez S, Somalo S, Moreno MA, Torres C, et al. Prevalence and diversity of extended-spectrum b-lactamases in faecal Escherichia coli isolates from healthy humans in Spain. Eur Soc Clin Microbiol Infect Dis. 2009;15:954-60.

10. Ben SR, Ben SLK, Saenz Y, Rojo-Bezares B, Estepa V, Jouini A, et al. Prevalence and characterization of extended-spectrum beta lactamase (ESBL) and CMY-2 producing Escherichia coli isolates from healthy food producing animals in Tunisia. Foodborne Pathog Dis. 2012;9:1137.

11. Blaak H, Van HAHAM, Veenman C, Van LAED, Lynch G, Van OWM, et al. Extended spectrum B-lactamase and constitutively AmpC-producing Enterobacteriaceae on fresh produce and in the agricultural environment. Int J Food Microbiol. 2014;168:8-16. https://doi.org/10.1016/j.jifoodmicro. 2013.10 .006

12. Durso LM, Cook KL. Impacts of antibiotic use in agriculture: what are the benefits and risks? Curr Opin Microbiol. 2014;19:37-44. https://doi.org/10. 1016/j.mib.2014.05.019.

13. Holmberg SD, Osterholm MT, Senger KA, Cohen ML. Drug-resistant Salmonella from animals fed antimicrobials. N Engl J Med. 1984;311:617-22.

14. Cohen ML, Tauxe RV. Drug resistant Salmonella in the United States: An epidemiologic perspective. Science. 1986;234:964-9.

15. Angulo FJ, Johnson KR, Cohen ML. Origins and consequences of antimicrobial-resistant nontyphoidal Salmonella: implications for the use of fluoroquinolones in food animals. Microb Drug Resist. 2000;6:77-83.

16. Threlfall EJ, Ward LR, Frost JA, Willshaw GA. The emergence and spread of antibiotic resistance in food-borne bacteria. Int J Food Microbiol. 2000;62:15.

17. White DG, McDermott PF. Emergence and transfer of antibacterial resistance. J Dairy Sci. 2001;84:151-5. https://doi.org/10.3168/jds.S0022 0302(01)70209-3.

18. AHI. Animal Health Ireland. 2017. http://animalhealthireland.ie/wp-content/ uploads/2017/10/20171027-JD-Technical-Manual-FINAL.pdf. Accessed 29 Nov 2018.

19. Official Journal of the European Union. Commission Implementing Decision 2013/652/EU of 12 November 2013 on the monitoring and reporting of antimicrobial resistance in zonotic and commensal bacteria. $L$ 303, 14.11 2013; 2013. p. 26-39. https://eur-europa.eu/LexUriServ/LexUriServ.do. Accessed 13 June 2019

20. http://epitools.ausvet.com.au/content.php?page=TestsHome. epitools.ausvet. com.au [Internet]. Available from: http://epitools.ausvet.com.au/content. php?page=TestsHome. Accessed 30 October 2019.

21. McHugh ML. Interrater reliability: the kappa statistic. Biochem Medica. 2012; 22(3):276-82.
22. Kim SG, Shin SJ, Jacobson RH, Miller LJ, Harpending PR, Stehman SM, et al. Development and application of quantitative polymerase chain reaction assay based on the ABI 7700 system (TaqMan) for detection and quantification of Mycobacterium avium subsp. paratuberculosis. J Vet Diagn Investig. 2002;14:126-31 Available from: http://www.ncbi.nlm.nih.gov/ entrez/query.fcgi?cmd=Retrieve\&db=PubMed\&dopt=Citation\&list_uids=1193 9333.

23. Barclay R, Ratledge C. Iron-binding compounds of Mycobacterium avium, M. intracellulare, M. scrofulaceum, and mycobactin-dependent M. paratuberculosis and M. avium. J Bacteriol. 1983;153:1138-46.

24. Tasara T, Stephan R. Development of an F57 sequence-based real-time PCR assay for detection of Mycobacterium avium subsp. paratuberculosis in milk. Appl Environ Microbiol. 2005;71:5957-68 Available from: http://www.ncbi. nlm.nih.gov/pubmed/16204510.

25. Lombard JE, Byrem TM, Wagner BA, McCluskey BJ. Comparison of milk and serum enzyme-linked immunosorbent assays for diagnosis of Mycobacterium avium subspecies paratuberculosis infection in dairy cattle. J Vet Diagn Investig. 2006;18:448-58 Available from: http://www.ncbi.nlm.nih. gov/pubmed/17037612.

26. Prendergast DM, Pearce RA, Yearsley D, Ramovic E, Egan J. Evaluation of three commercial PCR kits for the direct detection of Mycobacterium avium subsp. paratuberculosis (MAP) in bovine faeces. Vet J. 2018;241:52-7. https:// doi.org/10.1016/j.tvjl.2018.09.013.

27. Sting R, Hrubenja M, Mandl J, Seemann G, Salditt A, Waibel S. Detection of Mycobacterium avium subsp. paratuberculosis in faeces using different procedures of pre-treatment for real-time PCR in comparison to culture. Vet J. 2014;199:138-42 Available from: http://www.sciencedirect.com/science/ article/pii/S1090023313004164.

28. Lautenbach E, Bilker WB, Tolomeo P, Maslow JN. Impact of diversity of colonizing strains on strategies for sampling Escherichia coli from fecal specimens. J Clin Microbiol. 2008;46:3094-6.

29. Wasyl D, Hoszowski A, Zaj M, Szulowski K. Antimicrobial resistance in commensal Escherichia coli isolated from animals at slaughter. Front Microbiol. 2013;4:1-12

30. Hasman H, Agerse Y, Hendriksen R, Cavao LM, Guerra-Roman, Beatriz, Bortolaia V, Hendriksen R. European Union Reference Laboratory, DTU Food, National Food Institute. Isolation of ESBL, AmpC and carbapenemaseproducing E. coli from caecal samples. 2018. Accessed 28/05/2019.

31. ISO 6579:2002/Amd 1. International organization for standardization, Geneva, Switzerland. Detection of Salmonella spp. in animal faeces and in environmental samples from the primary production stage, amendment 1 , annex D. in Microbiology of food and animal feeding stuffs. Horizontal method for the detection of Salmonella spp. 2007. Accessed 28 March 2019.

32. Clark AE, Kaleta EJ, Arora A, Wolk M. Matrix-assisted laser desorption ionizationtime of flight mass spectrometry: a fundamental shift in the routine practice of clinical microbiology. Clin Microbiol Rev. 2013;26:547-603.

33. Kralik P, Beran V, Pavlik I. Enumeration of Mycobacterium avium subsp. paratuberculosis by quantitative real-time PCR, culture on solid media and optical densitometry. BMC Res Notes. 2012;5(1):114 Available from: http:// www.biomedcentral.com/1756-0500/5/114.

34. EFSA. European Food Safety Authority. 2016. https://www.eurl-ar.eu/ CustomerData/Files/Folders/3-workshop-kgs-lyngby-april2016/25_efsa-eusramr-workflow-and-criteria-for-esbl-ampc-carbapenemase-phenotypes.pdf. Accessed 28 Mar 2019.

35. Oliver SP, Jayarao BM, Almeida RA. Foodborne pathogens in milk and the dairy farm environment: food safety and public health implications. Foodborne Pathog Dis. 2005;2:115-29.

36. Nyberg KA, Vinnerås B, Ottoson JR, Aronsson P, Albihn A. Inactivation of Escherichia coli 0157:H7 and Salmonella Typhimurium in manure-amended soils studied in outdoor lysimeters. Appl Soil Ecol. 2010;46:398-404. Available from:. https://doi.org/10.1016/j.apsoil.2010.10.004.

37. Salgado M, Collins MT, Salazar F, Kruze J, Bölske G, Söderlund R, et al. Fate of Mycobacterium avium subsp. paratuberculosis after application of contaminated dairy cattle manure to agricultural soils. Appl Environ Microbiol. 2011;77:2122-9.

38. Toth JD, Aceto HW, Rankin SC, Dou Z. Survey of animal-borne pathogens in the farm environment of 13 dairy operations. J Dairy Sci. 2013;96:5756-61. https://doi.org/10.3168/jds.2012-6499.

39. Toth IK, van der Wolf JM, Saddler G, Lojkowska E, Helias V, Pirhonen M, et al. Dickeya species: an emerging problem for potato production in Europe. Plant Pathol. 2011;60:385-99. 
40. Jamieson RC, Gordon RJ, Sharples KE, Stratton GW, Madani A. Movement and persistence of fecal bacteria in agricultural soils and subsurface drainage water: a review. Can Biosyst Eng. 2002;44:1-9.

41. Norby B, Fosgate GT, Manning EJB, Collins MT, Roussel AJ. Environmental mycobacteria in soil and water on beef ranches: association between presence of cultivable mycobacteria and soil and water physicochemical characteristics. Vet Microbiol. 2007;124:153-9.

42. Lombard JE, Wagner BA, Smith RL, McCluskey BJ, Harris BN, Payeur JB, et al. Evaluation of environmental sampling and culture to determine Mycobacterium avium subspecies paratuberculosis distribution and herd infection status on US dairy operations. J Dairy Sci. 2006;89:4163-71 Available from: http://linkinghub.elsevier.com/retrieve/pii/S0022030206724614.

43. Collins MT, Gardner IA, Garry FB, Roussel AJ, Wells SJ. Consensus recommendations on diagnostic testing for the detection of paratuberculosis in cattle in the United States. J Am Vet Med Assoc. 2006;229:1912-9 Available from: http://avmajournals.avma.org/doi/abs/10.2460/javma.229.12.1912.

44. Berghaus RD, Farver TB, Anderson RJ, Jaravata CC, Gardner IA. Environmental sampling for detection of Mycobacterium avium ssp. paratuberculosis on large California dairies. J Dairy Sci. 2006;89:963-70 Available from: http://linkinghub. elsevier.com/retrieve/pii/S0022030206721610.

45. Mueller-Doblies D, Sayers AR, Mas-Carrique JJ, Davies RH. Comparison of sampling methods to detect Salmonella infection of Turkey flocks. J Appl Microbiol. 2009;107:635-45.

46. Bannantine JP, Barrietta RG, Stabel JR, Paustian ML, Kapur V. Application of the genome sequence to address concerns that Mycobacterium avium subspecies paratuberculosis might be a foodborne pathogen. Foodborne Pathog Dis. 2004;1:3

47. Ayele WY, Svastova P, Roubal P, Bartos M, Pavlik I. Mycobacterium avium subspecies paratuberculosis cultured from locally and commercially pasteurized cow's milk in the Czech Republic. Appl Environ Microbiol. 2005;71:1210-4.

48. Hruska K, Slana I, Kralik P, Pavlik I. Mycobacterium avium subsp. paratuberculosis in powdered infant milk: F57 competitive real time PCR. Vet Med (Praha). 2011;2011:226-30.

49. Reddacliff LA, Marsh IB, Fell SA, Austin SL, Whittington RJ. Isolation of Mycobacterium avium subspecies paratuberculosis from muscle and peripheral lymph nodes using acid-pepsin digest prior to BACTEC culture. Vet Microbiol. 2010;145:122-8.

50. Gill CO, Saucier L. Mycobacterium avium subsp. paratuberculosis in dairy products, meat, and drinking water. J Food Prot. 2011;74:480-99.

51. Klanicova B, Slana I, Vondruskova H, Kaevska M. Real-time quantitative PCR detection of Mycobacterium avium subspecies in meat products. J Food Prot. 2011;74:636-40

52. Pribylova R, Slana I, Kralik P, Kralova A, Babak V, Pavlik I. Correlation of Mycobacterium avium subsp. paratuberculosis counts in gastrointestinal tract, muscles of the diaphragm and the masseter of dairy cattle and potential risk for consumers. Int J Food Microbiol. 2011;151:314-8. https://doi.org/10 1016/j.ijfoodmicro.2011.09.025.

53. Whittington R, Donat K, Weber MF, Kelton D, Nielsen SS, Eisenberg S, et al. Control of paratuberculosis: who, why and how. A review of 48 countries. BMC Vet Res. 2019;15(198):1-29.

54. Geraghty T, Graham DA, Mullowney P, More SJ. A review of bovine Johne's disease control activities in 6 endemically infected countries. Prev Vet Med. 2014;116:1-11.

55. Good M, Clegg T, Sheridan H, Yearsely D, O'Brien T, Egan J, et al. Prevalence and distribution of paratuberculosis (Johne's disease) in cattle herds in Ireland. Ir Vet J. 2009;62:597-606 Available from: http://irishvetjournal. biomedcentral.com/articles/10.1186/2046-0481-62-9-597.

56. McAloon CG, Doherty ML, Whyte P, O'Grady L, More SJ, Messam LLMV, et al. Bayesian estimation of prevalence of paratuberculosis in dairy herds enrolled in a voluntary Johne's disease control Programme in Ireland. Prev Vet Med. 2016;128:95-100.

57. Cashman W, Buckley J, Quigley T, Fanning S, Egan J, Berry D, et al. Risk factors for the introduction and within-herd transmission of Mycobacterium avium subspecies paratuberculosis (MAP) infection on 59 Irish dairy herds. Ir Vet J. 2008;61:464-7.

58. Osterstock JB, Fosgate GT, Norby B, Manning EJB, Collins MT, Roussel AJ. Contribution of environmental mycobacteria to false-positive serum ELISA results for paratuberculosis. J Am Vet Med Assoc. 2007;230:896-901.

59. Holden NM, Fitzgerald D, Ryan D, Tierney H, Murphy F. Rainfall climate limitation to slurry spreading in Ireland. Agric For Meteorol. 2004;122: 207-14.
60. O'Mara F. Country Pasture/forage resource profiles. 2008 Available at [Cited 2017 Jun 7]. Available from: http://www.fao.org/ag/AGP/AGPC/doc/pasture/forage.htm

61. Varges R, Marassi CD, Oelemann W, Lilenbaum W. Interference of intradermal tuberculin tests on the serodiagnosis of paratuberculosis in cattle. Res Vet Sci. 2009;86:371-2.

62. Kennedy AE, da Silva AT, Byrne N, Govender R, MacSharry J, O'Mahony J, et al. The single intradermal cervical comparative test interferes with Johne's disease ELISA diagnostics. Front Immunol. 2014;5:564.

63. Good M. Bovine tuberculosis eradication in Ireland. Ir Vet J. 2006;59:153-62.

64. OIE 2012. World Organisations for Animal Health. www.oie.int/doc/ged/D12 008.pdf. Accessed 29 Mar 2019.

65. Clark DL, Koziczkowski JJ, Radcliff RP, Carlson RA, Ellingson JLE. Detection of Mycobacterium avium subspecies paratuberculosis: Comparing fecal culture versus serum enzyme-linked immunosorbent assay and direct fecal polymerase chain reaction. J Dairy Sci. 2008;91:2620-7 Available from: http://linkinghub.elsevier.com/retrieve/pii/S0022030208711378.

66. Whitlock RH, Wells SJ, Sweeney RW, Van Tiem J. ELISA and fecal culture for paratuberculosis (Johne's disease): sensitivity and specificity of each method. Vet Microbiol. 2000;77:387-98.

67. McKenna SL, Sockett DC, Keefe GP, McClure J, VanLeeuwen JA, Barkema HW. Comparison of two enzyme-linked immunosorbent assays for diagnosis of Mycobacterium avium subsp. paratuberculosis. J Vet Diagn Investig. 2005; 17:463-6 Available from http://www.ncbi.n/m.nih.gov/pubmed/16312239.

68. Stabel JR. An improved method for cultivation of Mycobacterium paratuberculosis from bovine fecal samples and comparison to three other methods. J Vet Diagn Investig. 1997;9:375-80 Available from: http://www. ncbi.nlm.nih.gov/pubmed/9376426.

69. Donat K, Kube J, Dressel J, Einax E, Pfeffer M, Failing K. Detection of Mycobacterium avium subspecies paratuberculosis in environmental samples by faecal culture and real-time PCR in relation to apparent within-herd prevalence as determined by individual faecal culture. Epidemiol Infect. 2015;143(2015):975-85.

70. Aly SS, Anderson RJ, Whitlock RH, Fyock TL, Mcadams S, Adaska JM, et al. Reliability of environmental sampling to quantify Mycobacterium avium subspecies paratuberculosis on California free-stall dairies. J Dairy Sci. 2009; 92(8):3634-42. https://doi.org/10.3168/jds.2008-1680.

71. Lavers CJ, Mckenna SLB, Dohoo IR, Barkema HW, Keefe GP. Evaluation of environmental fecal culture for Mycobacterium avium subspecies paratuberculosis detection in dairy herds and association with apparent within-herd prevalence. Can Vet J. 2013;54:1053-60.

72. Aly SS, Mangold BL, Whitlock RH, Sweeney RW, Anderson RJ, Jiang J, et al. Correlation between Herrold egg yolk medium culture and real-time quantitative polymerase chain reaction results for Mycobacterium avium subspecies paratuberculosis in pooled fecal and environmental samples. J Vet Diagn Investig. 2010;22:677-83.

73. Logar K, Kopinč R, Bandelj P, Starič J, Lapanje A, Ocepek M. Evaluation of combined high-efficiency DNA extraction and real-time PCR for detection of Mycobacterium avium subsp. paratuberculosis in subclinically infected dairy cattle: comparison with faecal culture, milk real-time PCR and milk ELISA. BMC Vet Res. 2012:8:1-10.

74. Stabel JR, Bannantine JP. Development of a nested PCR method targeting a unique multicopy element, ISMap02, for detection of Mycobacterium avium subsp. paratuberculosis in fecal samples. J Clin Microbiol. 2005;43:4744-50.

75. Leite FL, Stokes KD, Robbe-austerman S, Stabel JR. Comparison of fecal DNA extraction kits for the detection of Mycobacterium avium subsp. paratuberculosis by polymerase chain reaction. J Vet Diagn Investig. 2013;25:27-34.

76. Fock-Chow-Tho D, Topp E, Ibeagha-Awemu EA, Bissonnette N. Comparison of commercial DNA extraction kits and quantitative PCR systems for better sensitivity in detecting the causative agent of paratuberculosis in dairy cow fecal samples. J Dairy Sci. 2017;100:572-81.

77. Englund S, Bölske G, Johansson KE. An IS900-like sequence found in a Mycobacterium sp. other than Mycobacterium avium subsp. paratuberculosis. FEMS Microbiol Lett. 2002;209:267-71.

78. Eisenberg SWF, Nielen M, Santema W, Houwers DJ, Heederik D, Koets AP. Detection of spatial and temporal spread of Mycobacterium avium subsp. paratuberculosis in the environment of a cattle farm through bio-aerosols. Vet Microbiol. 2010;143:284-92.

79. Eisenberg S, Nielen M, Hoeboer J, Rutten V, Heederik D, Koetsa P. Environmental contamination with Mycobacterium avium subspecies paratuberculosis within and around a dairy barn under experimental 
conditions. J Dairy Sci. 2012;95:6477-82 Available from: http://www.ncbi. nlm.nih.gov/pubmed/22939786.

80. Eisenberg SW, Nielen M, Koets AP. Within-farm transmission of bovine paratuberculosis: recent developments. Vet Q. 2012;32(1):31-5.

81. Ramovic E, Yearsley D, Nighallchoir E, Quinless E, Galligan A, Markey B, et al. Mycobacterium avium subspecies paratuberculosis in pooled faeces and dust from the housing environment of herds infected with Johne's disease. Vet Rec. 2019;184:1-3.

82. Sweeney RW, Collins MT, Koets AP, Mcguirk SM, Roussel AJ. Paratuberculosis (Johne's disease) in cattle and other susceptible species. J Vet Intern Med. 2012:26:1239-50.

83. Kawaji S, Taylor DL, Mori Y, Whittington RJ. Detection of Mycobacterium avium subsp. paratuberculosis in ovine faeces by direct quantitative PCR has similar or greater sensitivity compared to radiometric culture. Vet Microbiol. 2007;125:36-48 [Cited 2018 Apr 7]. Available from: https:/www. sciencedirect.com/science/article/pii/S0378113507002301.

84. Klawonn W, Einax E, Pützschel R, Schmidt M, Donat K. Johne's disease: reliability of environmental sampling to characterize Mycobacterium avium subspecies paratuberculosis (MAP) infection in beef cow-calf herds. Epidemiol Infect. 2019;144(2016):2392-400.

85. Raizman EA, Espejo LA, Wells SJ. Long-term survival of Mycobacterium avium subsp. paratuberculosis in fecal samples obtained from naturally infected cows and stored at $-18^{\circ} \mathrm{C}$ and $-70^{\circ} \mathrm{C}$. Vet Med Int. 2011;1:341691.

86. Santos RL, Tsolis EM, Zhang S, Ficht TA, Baumler AJ, Adams LG. Salmonella induced cell death is not required for enteritis in calves. Infect Immun. 2001; 69:4610-7.

87. Dietz HH, Chriél M, Andersen TH, Jørgensen JC, Torpdahl M, Pedersen $H$, et al. Outbreak of Salmonella Dublin-associated abortion in Danish fur farms. Can Vet J. 2006;47:1201-5.

88. AFBI/DAFM. AFBI/DAFM. https:/www.agriculture.gov.ie/foodsafetyconsumerissues/ laboratoryservices/centralveterinarylaboratory/veterinaryresearchlaboratoryservice/ surveillancereports/. 2015. Accessed 27 May 2019.

89. Lomborg SR, Agerholm JS, Jensen AL, Nielsen LR. Effects of experimental immunosuppression in cattle with persistently high antibody levels to Salmonella Dublin lipopolysaccharide O-antigens. BMC Vet Res. 2007:3:1-6.

90. Costa LF, Paixão TA, Tsolis RM, Bäumler AJ, Santos RL. Salmonellosis in cattle: advantages of being an experimental model. Res Vet Sci. 2012;93:1-6. https://doi.org/10.1016/j.rvsc.2012.03.002.

91. Andino A, Hanning I. Salmonella enterica: Survival, colonization, and virulence Differences among serovars. Sci World J. 2015;2015:1-16.

92. Strohmeyer RA, Morley PS, Hyatt DR, Dargatz DA, Scorza AV, Lappin MR. Evaluation of bacterial and protozoal contamination of commercially available raw meat diets for dogs. J Am Vet Med Assoc. 2006;228(4): $537-42$.

93. Weese JS, Rousseau J, Arroyo L. Bacteriological evaluation of commercial canine and feline raw diets. Can Vet J. 2005;46:513-6.

94. Joffe DJ, Schlesinger DP. Preliminary assessment of the risk of Salmonella infection in dogs fed raw chicken diets. Can Vet J. 2002:43:441-2.

95. Rodrigues A, Pangloli P, Richards HA, Mount JR, Draughon FA. Prevalence of Salmonella in diverse environmental farm samples. J Food Prot. 2006;69(11):2576-80.

96. Marshall BM, Levy SB. Food animals and antimicrobials: impacts on human health. Clin Microbiol Rev. 2011;24:718-33.

97. Chattopadhyay MK. Use of antibiotics as feed additives: a burning question. Front Microbiol. 2014;5:1-3.

98. Davies MR, Broadbent SE, Harris SR, Thomson NR, der Woude MW Van V. Horizontally acquired glycosyltransferase operons drive Salmonellae lipopolysaccharide diversity. PLoS Genet. 2013;9:e1003568.

99. O'Neill J. Review on antimicrobial resistance. Antimicrobials in agriculture and the environment: Reducing unnecessary use and waste. 2015. https:// amr-review.org/sites/default/files/Antimicrobials\%20in\%20agriculture\%2 Oand\%20the\%20environment\%20-\%20Reducing\%20unnecessary\%20use\%2 Oand\%20waste.pdf. Accessed 04 April 2019.

100. Hutchison ML, Walters LD, Avery SM, Synge BA, Moore A. Levels of zoonotic agents in British livestock manures. Lett Appl Microbiol. 2004;39:207-14.

101. Oppegaard H, Steinum TM, Wasteson Y. Horizontal transfer of a multi-drug resistance plasmid between coliform bacteria of human and bovine origin in a farm environment. Appl Environ Microbiol. 2001;67:3732-4.

102. Monira S, Shabnam SA, Ali SI, Johura F-T, Rahman ZK, ALam HN, et al. Multidrug resistant pathogenic bacteria in the gut of young children in Bangladesh. Gut Pathog. 2017;9:19.
103. Ingle DJ, Levine MM, Kotloff KL, Holt KE, Robins-Browne RM. Escherichia coli from children in community settings in South Asia and sub-Saharan Africa. Nat Microbiol. 2018;3:1063-73. https://doi.org/10.1038/s41564-018-0217-4.

104. Aarestrup FM, Ahrens P, Madsen M, Pallesen LV, Poulsen RL, Westh H. Glycopeptide susceptibility among Danish enterococcus faecium and enterococcus faecalis isolates of animal and human origin and PCR identification of genes within the VanA cluster. Antimicrob Agents Chemother. 1996:40:1938-40.

105. van den Bogaard AEJM, London N, Stobberingh EE. Antimicrobial resistance in pig faecal samples from the Netherlands (five abattoirs) and Sweden. J Antimicrob Chemother. 2000;45:663-71.

106. Ashbolt NJ, Amézquita A, Backhaus T, Borriello P, Brandt KK, Collignon P, et al. Human health risk assessment (HHRA) for environmental development and transfer of antibiotic resistance. Environ Health Perspect. 2013;121:993-1001.

107. Roussel AJ. Control of paratuberculosis in beef cattle, Veterinary Clinics of North America. Food Animal Pract. 2011;27:593-8.

108. Allen HK, Donato J, Wang Huimi H, Cloud-Hansen KA, Davies J, Handelsman J. Call of the wild: antibiotic resistance genes in natural environments. Nat Rev Microbiol. 2010;8:251-9.

109. Skurnik D, Clermont O, Guillard T, Launay A, Danilchanka O, Pons S, et al. Emergence of antimicrobial-resistant Escherichia coli of animal origin spreading in humans. Mol Biol Evol. 2015;33:898-914.

110. Bolton DJ, Ennis C, Mcdowell D. Occurrence, virulence genes and antibiotic resistance of enteropathogenic Escherichia coli (EPEC) from twelve bovine farms in the north-east of Ireland. Zoonoses Public Health. 2014;61:149-56.

111. EMEA. The European Agency for the Evaluation of Medicinal Products. Antibiotic resistance in the European Union associated with therapeutic use of veterinary medicines. 1999. https://www.ema.europa.eu/en/documents/ report/antibiotic-resistance-european-union-associated-therapeutic-useveterinary-medicines-report_en.pdf. Accessed 27 May 2019.

112. Nováková I, Kačniová M, Haščik P, Pavličová S, Hleba L. The resistance to antibiotics in strains of E.Coli and Enterococcus sp. Isolated from rectal swabs of lambs and calves. SPASB. 2009:42:322-6.

113. Bush K, Jacoby GA. Updated functional classification of beta-lactamases. Antimicrob Agents Chemother. 2010;54:969-76.

114. Pfeifer Y, Cullik A, Witte W. Resistance to cephalosporins and carbapenems in Gram-negative bacterial pathogens. Int J Med Microbiol. 2010;300:371-9 https://doi.org/10.1016/j.jijmm.2010.04.005.

115. Cullik A, Pfeifer Y, Prager R, Von Baum H, Witte W. A novel IS26 structure surrounds Bla (Bla superscript) CTX-M genes in different plasmids from German clinical Escherichia coli isolates. J Med Microbiol. 2010;10:580-7.

116. Moritz VA, Carson PBD. Cefoxitin sensitivity as a marker for inducible betalactamases. J Med Microbiol. 1986;21:203-7.

117. Livermore DM, Winstanley TG, Shannon KP. Interpretative reading: recognizing the unusual and inferring resistance mechanisms from resistance phenotypes. J Antimicrob Chemother. 2001;48:87-102.

118. CLSI. Clinical and Laboratory Standards Institute. 4th ed; 2013. https://clsi. org/media/2321/vet08ed4_sample.pdf. Accessed 23 May 2019

119. O'Sullivan M, Burns K, Slowey R, Byrne W, Samin D. Government of Ireland; First One Health report and antimicrobial use and antimicrobial resistance, 2016. 2019. https://health.gov.ie/wp-content/uploads/2019/01/One-HealthReport-on-Antimicrobial-Use-Antimicrobial-Resistance.pdf.

120. HPRA 2014. Health Products Regulatory Authority. http://www.hpra.ie/ homepage/veterinary/special-topics/antibiotic-resistance. Accessed 06 June 2019.

121. Collignon PC, Conly JM, Andremont A, Mcewen SA, Aidara-Kane A. World health organization ranking of antimicrobials according to their importance in human medicine: a critical step for developing risk management strategies to control antimicrobial resistance from food animal production. Clin Infect Dis. 2016;63(8):1087-93.

122. Lambrecht E, Bare J, Sabbe K, Houf K. Impact of Acanthamoeba cysts on stress resistance of Salmonella enterica Serovar Typhimurium, Yersinia enterocolitica 4/O:3, Listeria monocytogenes 1/2a, and Escherichia coli O:26. Appl Environ Microbiol. 2017;83(14):1-9.

123. HPRA. Health Product Regulatory Authority. 2016. https://www.ema.europa. eu/en/documents/annual-report/annual-report-european-agency-evaluationmedicinal-products-1999_en.pdf. p. http://www.hpra.ie/mwg-internal/de5 fs23hu73ds/prog. Accessed 27 May 2019.

\section{Publisher's Note}

Springer Nature remains neutral with regard to jurisdictional claims in published maps and institutional affiliations. 